\title{
Comparison Of Development Effects For Two Different Combined Well Patterns With Horizontal Wells And Vertical Wells
}

\author{
Qingyan X $\mathbf{u}^{*}$, Research Institute of Petroleum Exploration and Development, Petrochina, \\ Beijing, China; Rongliang Guan, Daqing NO.1 Drilling Company of Daqing Drilling Ltd, \\ Petrochina, Daqing, China; Cong Wu, Research Institute of Petroleum Exploration \& \\ Development, Huabei Oilfield Branch, Petrochina, Zhengzhou, China
}

\begin{abstract}
In recent years, horizontal wells have been widely utilized in low permeability reservoirs of China. Normally horizontal wells are deployed combined with vertical wells, in which way effective injectionproduction well network system could be established. However, horizontal wells could be water injectors as well as oil producers and the same is true for vertical wells. The adoption of which kind of combined well pattern has been in dispute for a long time. In response to this issue, a novel physical simulation system is utilized to contrast the development effect of two well patterns with horizontal wells and vertical wells together. By comparing pressure gradient and flow velocity, the better scenario can be selected. If the horizontal well is not fractured, well pattern of horizontal wells as injectors with vertical wells as producers has a remarkable advantage. While the horizontal well is fractured, well pattern of horizontal wells as producers with vertical wells as injectors has a clear advantage. From another perspective to analyze the result, if an oilfield needs horizontal well to inject water for vertical wells, then the horizontal well is suggested not to be fractured. If an oilfield needs horizontal wells to produce much more oil with vertical injection wells, then horizontal wells with multiple hydraulic fractures could obtain better effect. As a rule of thumb, deployment of horizontal wells as oil producers is more common in oilfields.
\end{abstract}

\section{Introduction}

Application of horizontal wells and vertical wells combined is an effective technology to improve the development effect of low permeability reservoirs in China (Cai et al. 2009; Zeng et al. 2010). With respect to the combined well patterns (Cai et al. 2010; Xiong et al. 2012), there are two entirely different modes. One is setting horizontal wells as injectors and vertical wells as producers (HIVP), and the other one is on the contrary, i.e. horizontal wells as producers and vertical wells as injectors (HPIV). The adoption of which kind of combined well pattern has been in dispute for a long time and little literature involves research for this issue.

Large-scale slab model made of natural outcrop core is an effective tool to study seepage mechanism in low permeability reservoirs. In this paper, we present a novel physical simulation system to contrast the two approaches to optimize the more reasonable scenario. 


\section{Manuscript Presentation}

To carry out the slab model physical simulation experiment, several working procedures are essential, including natural outcrop screening, flat model fabrication, packaging, vacuum, water saturation, and flow field measurement. Detailed process of the large-scale slab model can be found in the following reference (Xu et al. 2012). The system of physical simulation has four sections: injecting system, natural outcrop slab, producing system and measuring system, as shown in Figure 1.

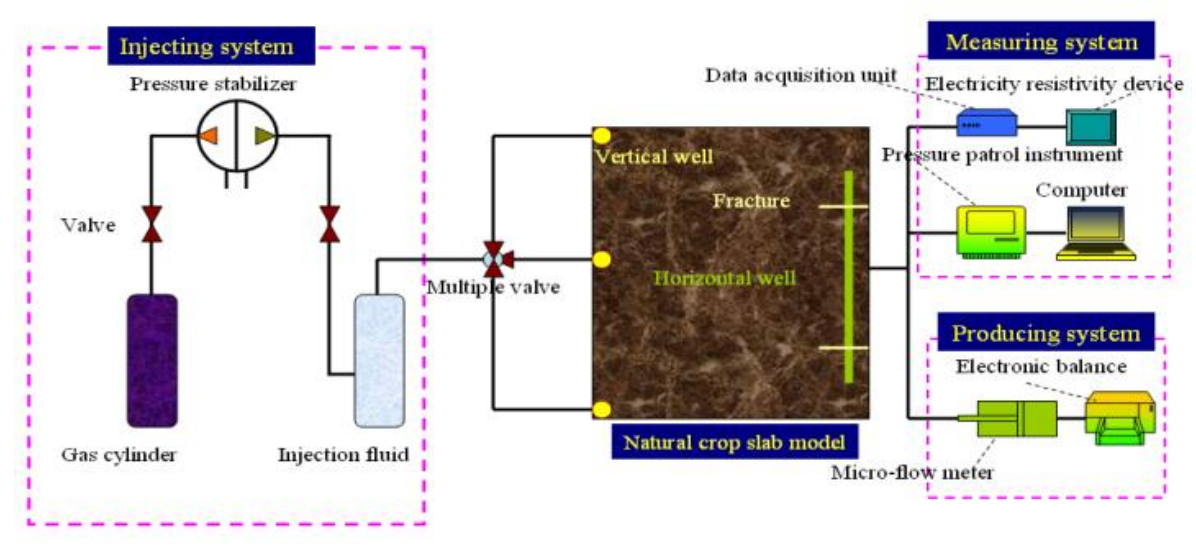

Figure 1-Flow diagram of physical simulation

In order to determine the better well pattern, horizontal well with fracture and without fracture are both considered, as shown in Figures 2 and 3. Pressure gradient distribution and flow velocity can be obtained by pressure patrol instrument and micro-flow meter respectively. According to Darcy Law, flow rate or flow velocity in porous media is proportional to the pressure gradient. In other words, the value or level of pressure gradient can reflect the degree of difficulty for displacement.
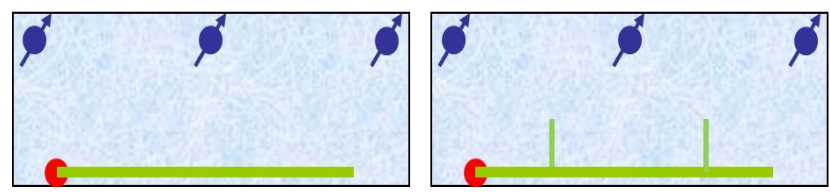

Figure 2-HPVI without fractures and with fractures
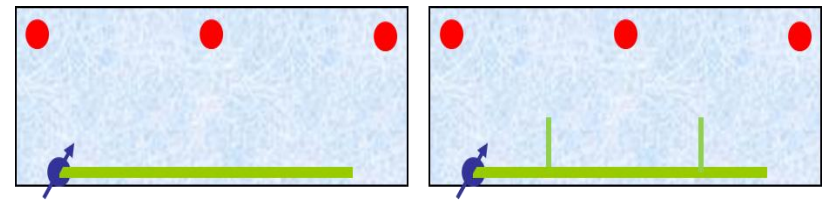

Figure 3-HIVP without fractures and with fractures

The size of the slab model is $0.4 \mathrm{~m} \times 0.4 \mathrm{~m}$ and the length of two fractures is $0.05 \mathrm{~m}$. As shown in Figures 4 and 5, pressure gradient distribution of the two well patterns is provided when the displacement pressure difference is $30 \mathrm{KPa}$. Pressure gradient around injectors and producers is higher than the region between wells.

Also when the horizontal well is fractured, the pressure gradient nearby the fractures becomes higher. Low pressure gradient reveals high degree of difficulty for displacement, while high pressure gradient is the opposite.

While the horizontal well is not fractured, as a whole the pressure gradient of HIVP pattern is slightly greater than that of HPVI pattern, reflecting horizontal well as injectors has an advantage. While the horizontal well is fractured, the pressure gradient of HPVI pattern is significantly higher than that of HIVP pattern, reflecting horizontal well as produces has a clear advantage. 

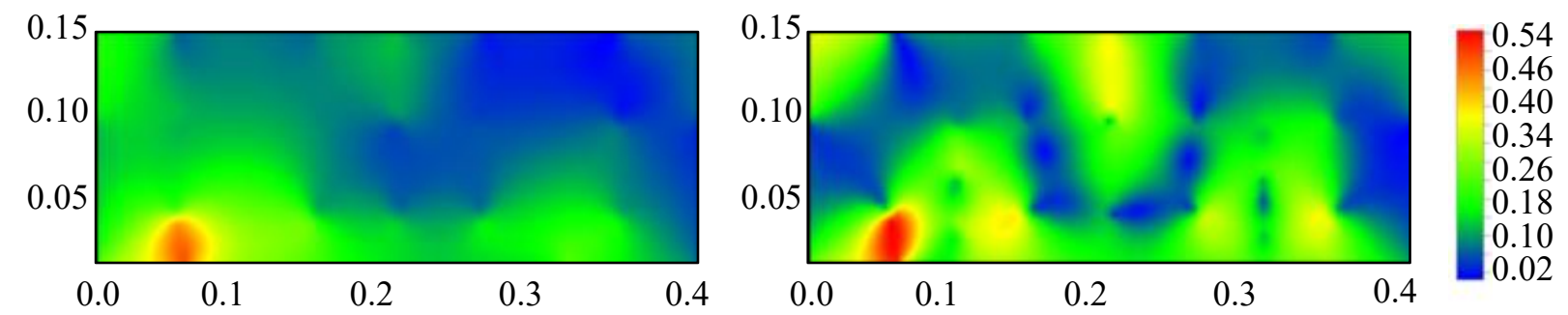

Figure 4-Pressure gradient distribution of HPVI without fractures and with fractures
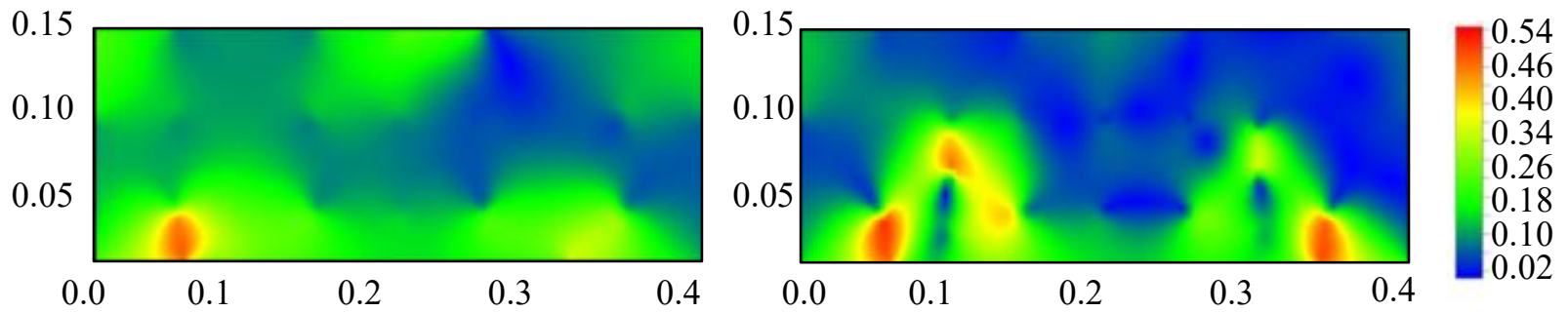

Figure 5-Pressure gradient distribution of HIVP without fractures and with fractures

As shown in Figures 6 and 7, the flow velocity of HIVP pattern is slightly greater than that of HPVI pattern, also reflecting horizontal well as injectors has an advantage when the horizontal well is not fractured. While the horizontal well is fractured, the flow velocity of HPVI pattern is significantly higher than that of HIVP pattern, also reflecting horizontal well as produces has a clear advantage after hydraulic fractured.

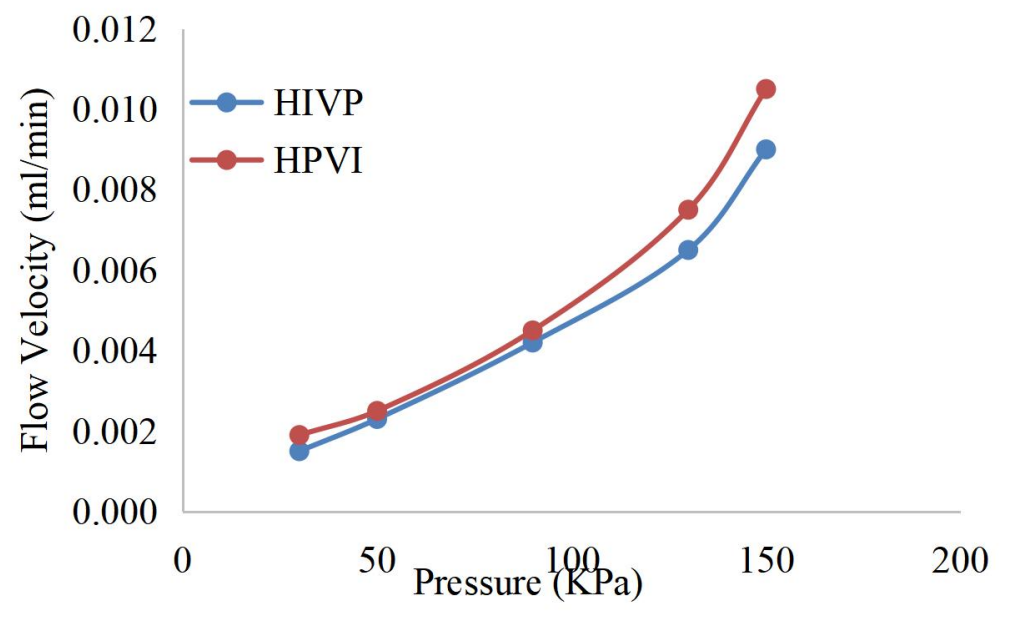

Figure 6-Flow velocity of HIVP and HPVI without fractures 


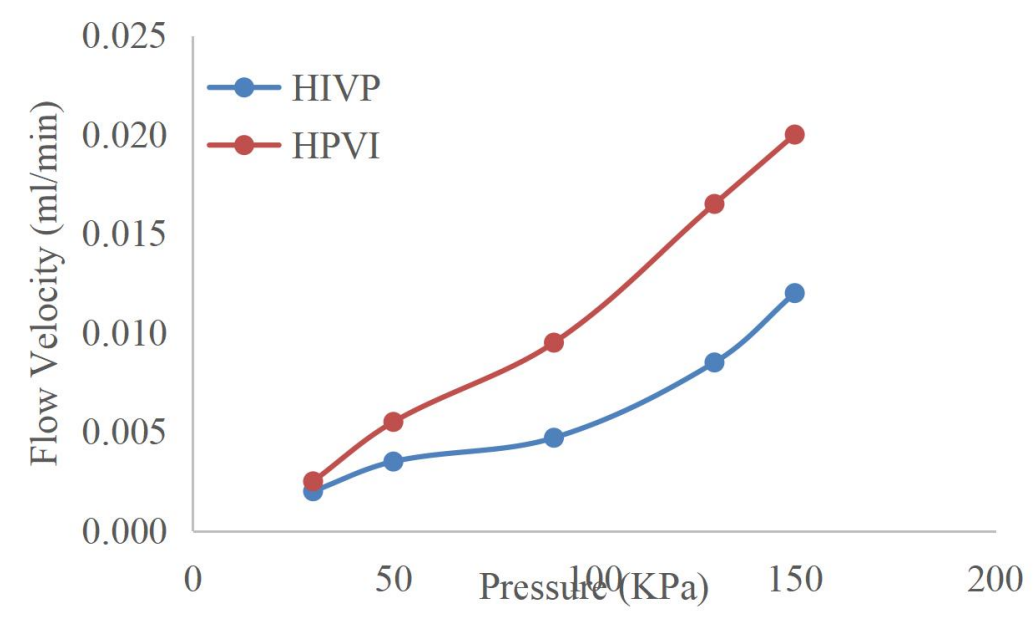

Figure 7-Flow velocity of HIVP and HPVI with fractures

\section{Conclusions and Discussions}

The present result may be useful for combined well pattern selection and adoption when horizontal wells are involved in the oilfield development. If the horizontal well is not fractured, well pattern of horizontal wells as injectors with vertical wells as producers could obtain better development effect. While the horizontal well is fractured, well pattern of horizontal wells as producers with vertical wells as injectors may result in better performance. From another perspective to analyse the result, if an oilfield needs horizontal well to inject water for vertical wells, then the horizontal well is suggested not to be fractured. If an oilfield needs horizontal wells to produce much more oil with vertical injection wells, then horizontal wells with multiple hydraulic fractures could obtain better effect. In general, deployment of horizontal wells as oil producers is more common in oilfields.

\section{Acknowledgments}

We sincerely thank the supports from National Science and Technology Major Project of China (No. 2011ZX05032 and No. 2011ZX05058). Also we thank the support from CNPC Project (NO.2016D-4402).

\section{Conflicts of Interest}

The author(s) declare that they have no conflicting interests.

\section{References}

Cai, W., Li, Z, and Zhang, X. 2009. Horizontal Well Fracturing Technology for Reservoirs with Low Permeability. Petroleum Exploration and Development 36(1):80-85

Cai, X., Tang, H., and Zhou, K. 2010. Pattern Optimization of Hydraulically Fractured Horizontal Wells in Low Permeability and Thin Interbedded Reservoirs. Special Oil and Gas reservoirs 17(4):72-74.

Xiong, Y., Liu, L., and Zhang, L. 2012. Present Status and Development Comments on Horizontal Well Completion Techniques in China. Petroleum Drilling Techniques 40(1):1-6.

Xu, X., Liu, X., and Yang, Z. 2012. An Experimental Study on Single-phase Seepage Characteristics with a Largescale Model Made of Ultra-low Permeability Sandstone Outcrops. Acta Petrolei Sinica 33(3):454-458.

Zeng, B., Cheng, L., and Li, C. 2010. Development of Evaluation of Fractured Horizontal Wells in Ultra-low Permeability Reservoirs. Acta Petrolei Sinica 31(5):791-796.

Qingyan $\mathbf{X u}$ is a senior reservoir engineer at CNPC Research Institute of Petroleum Exploration and Development (Beijing), where he has worked for 7 years. His research interests are in low permeability reservoir development, complex fault block reservoir development, and super-deep water gas reservoir 
development. He holds bachelor and master degree from the China University of Petroleum, and Ph.D. from Chinese Academy of Sciences, all in oil \& gas field development.

Rongliang Guan is a senior drilling engineer at Daqing NO.1 drilling company of Daqing drilling Itd, where he has worked for 12 years. His research interests are in directional drilling and horizontal drilling. He holds bachelor degree from the China University of Petroleum in drilling.

Cong $\mathbf{W u}$ is a senior reservoir engineer at Research Institute of Petroleum Exploration \& Development of Huabei Oilfield Branch, where he has worked for 15 years. His research interests are in formation testing, acidizing and fracturing. He holds bachelor and master degree from the China University of Petroleum, both in oil \& gas field development. 